\title{
Hypomagnesemia As A Link to Dyslipidemia in Diabetes Mellitus
}

\author{
N. Manaswini, M. Noorjahan, K.S.S.Sai Baba, Priscilla Abraham chandran \\ Deparment of Biochemistry, Nizams institute of medical sciences, Hyderabad, India
}

\begin{abstract}
:
Aim and Objectives: To observe the association between magnesium and lipid parameters in type 2 diabetic patients.

Materials and methods: A case-control study consisted of control group (36 healthy individuals) and case group (50 patients who were diagnosed with type 2 diabetes). Serum magnesium and lipid profile wereanalysed in blood samples on automated analyser. The data was analysed using unpaired 't' test if the data is normally distributed and Mann-Whitney $U$ test if the data is not normally distributed. Spearman correlation analysis was done.

Results: In the present study, a significant low serum magnesium levels $(p<0.01)$ in case group was observed when compared to control group. A significantly higher triglycerides levels ( $p<0.05)$, increased TC/HDL ratio levels $(p<0.001)$ and increased Atherogenic index of plasma $(p<0.001)$ was observed in casesgroup when compared to control group. The fasting blood sugar and HbAlC showed statistically significant increase in cases than controls. A negative correlation was observed between magnesium and cholesterol $(r=-0.3$, $p<0.006)$, magnesium and LDL $(r=-0.2, p=0.03)$, magnesium and total cholesterol/HDL ratio $(r=-0.2$, $p=0.04)$.
\end{abstract}

Conclusion: Dyslipidemia observed in Type 2 Diabetes could be due to Hypomagnesemia.

Keywords: Diabetes, Lipid profile,Magnesium

\section{Introduction}

Magnesium is the second most common intracellular cation. It is required for insulin secretion, insulin receptor interaction, post receptor events (involving tyrosine kinase mediated phosphorylation) and normal carbohydrate utilization (by Mg dependent enzymes) (1). Magnesium is required for the activation of lipoprotein lipase and lecithin cholesterol acyl transferase which plays an important role in increasing HDL cholesterol and catabolism of triglycerides (2). So magnesium deficiency leads to increase in LDL-C (low density lipoproteins), VLDL (very low density lipoproteins) and decrease in HDL-C (high density lipoproteins). Magnesium is also a vital factor for apolipoprotein synthesis[3]. Itmainly formscomplexes with ATP. This ATP-Mg complex is the allosteric factor for the enzyme HMG-CoA reductase in cholesterol synthesis. Therefore, magnesium is called as natural statin[4,5].Pyrophosphatase plays an important role in the first reaction of lipolysis and magnesium is a cofactor for it [6]. In hypomagnesemia situations, these enzymes are defective and lead to dyslipidemia. Hence, in the present study we have decided to observe the association between hypomagnesemia and dyslipidemia in patients with type 2 diabetes mellitus patients.

\section{Materials And Methods}

The present study was conducted in the Department of Biochemistry, Nizam's Institute of Medical Sciences (NIMS), Hyderabad, India. Further, we have taken informed consent from the participating subjectsand followed Institutional Ethics committee protocol. Our study comprised of two groups. Case group consisted of Type 2 diabetes mellitus patients of both genders andcontrolgroup consisted of age and sex-matched apparently healthy subjects. Inclusion criteria are age above 30 years and with type 2 diabetes patients and on treatment with either oral hypoglycemic agents (OHA) or insulin.Patients on diuretics and presence of other chronic or acute infections were excluded from the study. Moreover, patients who areon phenothiazines, caffeine, nicotine, levodopa, morphine, steroids, oral contraceptives, alpha-interferon etc., were excluded.

Blood samples were collected from 86 study participants in the fasting state. Duration of diabetes, drug history, and BMI were recorded. Fasting plasma glucose, serum levels of magnesium $(\mathrm{Mg})$, creatinine, urea and lipid profile were measured by standard methods. Glycatedhemoglobin was measured by HPLC method. Statistical analyses were performed with graph pad prism 5 version. Results were expressed as mean \pm SD when the data is parametricand median (range) when the data is nonparametric. The two groups are compared using unpaired t test and Mann-Whitney $\mathrm{U}$ test when data is parametric and non-parametric respectively. $\mathrm{P}<0.05$ is taken as significant. 


\section{Results}

This is a case-control study comprising of 86 subjects, of which 50 patients were diabetic and 36 patients were apparently healthy controls.

Baseline characteristics

Table 1: Baseline Characteristics of Controls and cases

\begin{tabular}{|c|c|c|c|}
\hline Variable & Controls $n=36$ & Cases $\mathrm{n}=50$ & P value \\
\hline Age (yrs.) * & $54 \pm 12$ & $58 \pm 10$ & 0.81 \\
\hline Gender & $\begin{array}{l}\text { Males - } 21(59 \%) \\
\text { Females-15 (41\%) }\end{array}$ & $\begin{array}{l}\text { Males-30 }(60 \%) \\
\text { Females-20 (40\%) }\end{array}$ & \\
\hline BMI $\left(\mathrm{kg} / \mathrm{m}^{2}\right)^{\#}$ & $24(18-36)$ & $27(20-38)$ & $0.005^{x \times}$ \\
\hline
\end{tabular}

Data presented as *mean $\pm \mathrm{SD}$ when it is normal distribution and \#Median and range when not - normal distribution. ${ }^{*} \mathrm{P}<0.05$ is taken as significant.

Control group consisted of 36 healthy subjects, out of which 15 were females (41\%) and 21 were males (59\%). Similarly, among 50 diabetic patients in the case group, 20 were females $(40 \%)$ and 30 were males $(60 \%)$. The median value of BMI in diabetic patients issignificantly higher in cases $\left(27 \mathrm{~kg} / \mathrm{m}^{2}\right) \mathrm{when}$ compared to controls $\left(24 \mathrm{~kg} / \mathrm{m}^{2}\right)$.

Biochemical investigations

Table 2: Biochemical variables in controls and cases

\begin{tabular}{|c|c|c|c|}
\hline Variable & Controls & Cases & $P$ value \\
\hline FBS $^{\#}(\mathbf{m g} / \mathrm{dl})$ & $88(78-132)$ & $125(83-378)$ & $<0.0001^{\mathrm{xx}}$ \\
\hline HbA1C $^{*}(\%)$ & $5.4 \pm 0.3$ & $7.7 \pm 1.3$ & $<0.0001^{\text {×x }}$ \\
\hline Urea $^{*}(\mathrm{mg} / \mathrm{dl})$ & $23 \pm 1.4$ & $21 \pm 2.7$ & $>0.05$ \\
\hline Creatinine $^{\#}$ (mg/dl) & $0.9(0.5-1)$ & $0.7(0.5-2)$ & $<0.05^{\mathrm{xx}}$ \\
\hline Magnesium $^{\#}(\mathrm{mmol} / \mathrm{L})$ & $1(0.7-1.3)$ & $0.8(0.5-1.4)$ & $0.0001^{\mathrm{xx}}$ \\
\hline Total Cholesterol* (mg/dl) & $151 \pm 42$ & $164 \pm 50$ & 0.2 \\
\hline LDL-C ${ }^{*}(\mathrm{mg} / \mathrm{dl})$ & $86 \pm 27$ & $86 \pm 39$ & 0.9 \\
\hline HDL-C ${ }^{*}(\mathrm{mg} / \mathrm{dl})$ & $47 \pm 12$ & $42 \pm 9$ & 0.08 \\
\hline Triglycerides $^{\#}$ (mg/dl) & $104(28-239)$ & $125(29-520)$ & $0.008^{\mathrm{xx}}$ \\
\hline TC/HDL ${ }^{\#}$ & $3(2-7)$ & $4(1-7)$ & $0.02^{\times x}$ \\
\hline AIP* (logTG/HDL) & $0.3 \pm 0.25$ & $0.5 \pm 0.25$ & $<0.0001^{x x}$ \\
\hline
\end{tabular}

Data presented as *mean $\pm \mathrm{SD}$ when it is normal distribution and \#Median and range when not-normal distribution. ${ }^{\times *} \mathrm{P}<0.05$ is taken as significant.

The median value of fasting plasma glucose level in cases and controls is $125 \mathrm{mg} / \mathrm{dl}$ and $80 \mathrm{mg} / \mathrm{dl}$ respectively and it is significantly $(\mathrm{p}<0.0001)$ higher in cases than controls. SimilarlyGlycatedHemoglobin also showed higher levels in cases compared tocontrols which were statistically significant (Table 2). Among the lipid parameters the median triglycerides and total cholesterol to HDL-C ratio is significantly higher in cases than in controls $(\mathrm{p}=0.008, \mathrm{p}=0.02)$ respectively. The mean value of atherogenic index of plasma(AIP) in cases and controls is 0.5 and 0.3 respectively and it is significantly $(\mathrm{p}<0.0001)$ higher in cases. There is no statistically significant difference in serum Total cholesterol, LDL-C and HDL-C in cases and controls. The median value of serum magnesium level in cases and controls is $0.8 \mathrm{mmol} / \mathrm{L}$ and $1.0 \mathrm{mmol} / \mathrm{L}$ respectively and it is significantly $(\mathrm{p}=0.0001)$ lower in cases than in controls.
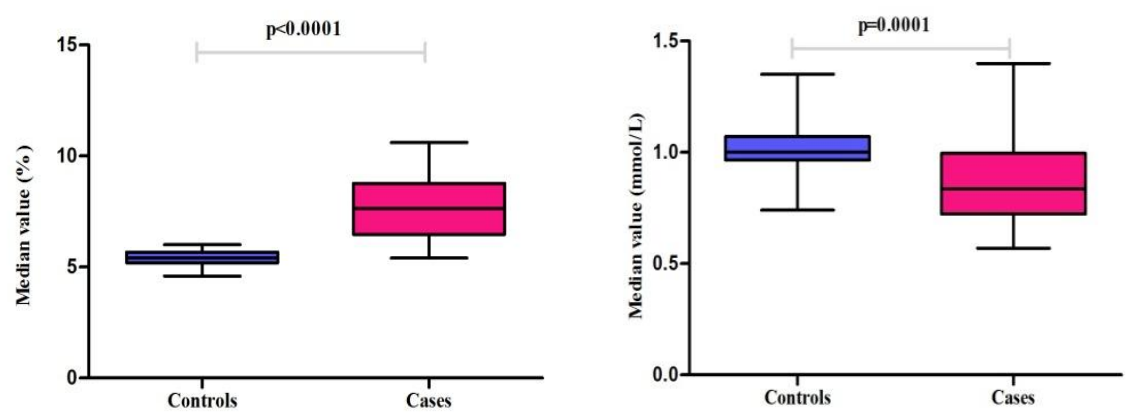

Fig 1: HbA1C in controls and cases Fig 2: Serum magnesium levels in controls and cases 
Table 3: Correlation of Magnesium with other variables:

\begin{tabular}{|l|l|l|}
\hline Variable & R & \multicolumn{1}{|c|}{ P value } \\
\hline BMI & -0.004 & 0.9 \\
\hline FBS & -0.02 & 0.8 \\
\hline Total cholesterol & -0.3 & $0.006^{\times}$ \\
\hline LDL-C & -0.4 & $0.03^{\times}$ \\
\hline HDL-C & -0.05 & 0.6 \\
\hline Triglyceride & -0.08 & 0.4 \\
\hline TC/HDL & -0.2 & $0.04^{\times}$ \\
\hline AIP & -0.17 & 0.1 \\
\hline HbA1C & -0.3 & $0.002^{\times}$ \\
\hline
\end{tabular}

Spearman correlation analysis was done as data is non parametric. $\mathrm{P}<0.05$ is considered as significant.

Serum magnesium has significant negative correlation with Total cholesterol $(\mathrm{P}=0.006)$, LDL-C $(\mathrm{P}=0.03), \mathrm{TC} / \mathrm{HDL}(\mathrm{P}=0.04)$ and $\mathrm{HbA1C}(\mathrm{P}=0.002)$ as shown in Table 3.
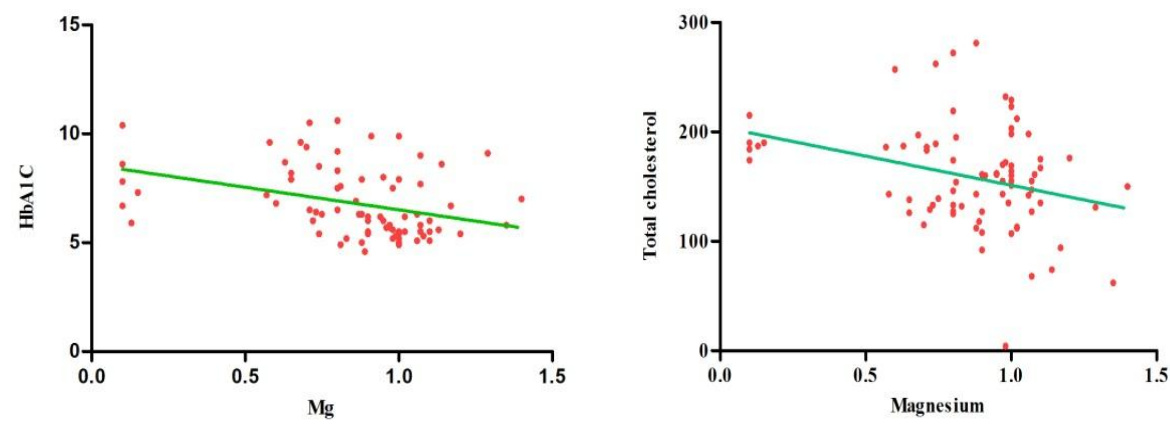

Fig 3: Correlation of magnesium with $\mathrm{HbA} 1 \mathrm{C}$

Fig 4: Correlation of magnesiumwith Total cholesterol

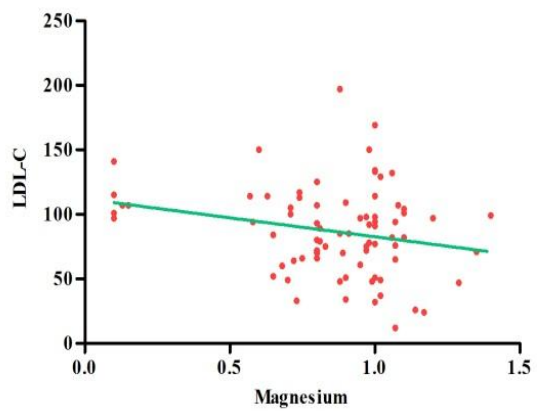

Fig 5: Correlation of magnesium with LDL-C

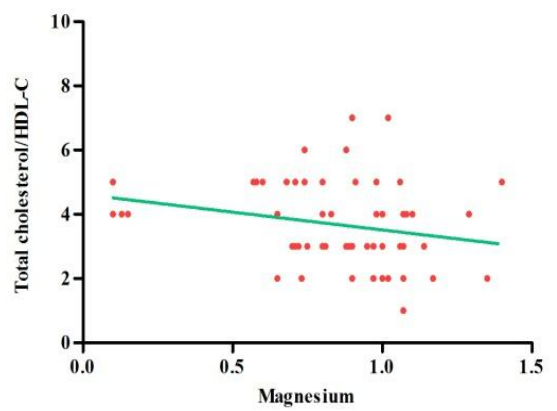

Fig 6: Correlation of magnesium with TC/HDL-C

\section{Discussion}

Several studies showed that there is an association between lipid metabolism disorders and magnesium deficiency in type 2 diabetes patients [7-9].In the present study we found an increase in serum triglyceride levels, total cholesterol to HDL ratio and atherogenic index of plasma in case group when compared to control group and also we found significant decrease in magnesium levels in cases when compared to controls. It suggests that magnesium deficiency can contribute to dyslipidemia.

In this study, we observed significant negative correlation of serum magnesium with total cholesterol,LDL cholesterol and total cholesterol HDL-C ratio. This is similar to the study done by Sasmita Mishra et al(10). This might point out the contributory role of magnesium towards dyslipidemia. The present study reports no correlation between serum magnesium and HDL cholesterol, serum triglycerides. Hamid Nasri and his colleagues also did not show anyassociation between these parameters[11]. Magnesium deficiency inactivates lipid metabolismenzymes which in turn lead to dyslipidemia. It is a cofactor for several enzymes involved in carbohydrate metabolism and its imbalance has been implicated in diabetes mellitus both as a cause and a consequence. In the gut, magnesium creates insoluble complexes with fatty acids and prevents the dietary fat absorption[12].

A significant negative correlation was found between serum magnesium and glycemic control. Magnesium is important for the effectiveness of insulin. Hypomagnesemia results in a defective tyrosine kinase 
activity at the insulin receptor level, as magnesium acts as a cofactor in the insulin signaling pathway. Poor glycemic control is the main reason for the development of various complications like dyslipidemia, retinopathy, nephropathy, etc[13, 14]. Oral magnesium administration had caused a fall in total cholesterol levels, LDL cholesterol levels, triglyceride levels and increase in HDL cholesterol levels [15, 16]. It has been proved in several studies that daily oral magnesium supplementation substantially improved insulin sensitivity by $10 \%$ and reduced blood sugar by $37 \%$ (17).

\section{Conclusion}

The current study shows hypomagnesemia and dyslipidemia in type 2 diabetic patients in comparison with healthy individuals. We observed significant negative correlation of magnesium with total cholesterol and LDL-C which might point out the contributory role of magnesium towards dyslipidemia. Studies with oral supplementation will be helpful to confirm the causative role of magnesium deficiency in the development of dyslipidemia.

\section{Conflicts of interest}

There is no conflict of interest.

\section{References}

[1]. AshimaBadyal,Kuldip Singh Sodhi, Rajesh Pandey, Jasbir Singh Serum Magnesium Levels:A Key Issue For Diabetes Mellitus. JK SCIENCE Vol. 13 No.3, July-September 2011.

[2]. Jennifer. L. King, Rita. J. Miller, James. P. Blue, William. D. O’Brien and John. W. Erdman. Inadequate Dietary magnesium in take increases atherosclerotic plaque development in rabbits. Nutr Res 2009; 29[5]: 343-349.

[3]. Gueux E, Rayssiguier Y, Piot MC and Alcindor L. Reduction of plasma lecithin cholesterol acyl transferase activity by acute magnesium deficiency in the rats. J Nutr 1984; 114:1479- 1483.

[4]. Kaur J, Prabhu KM and Thakur LC. Serum magnesium levels in ischaemic cerebrovascular disorders: a case control study in north Indian population. JPBMS 2012; 17[2]: 17.

[5]. Rasanoff A and Seeling MS. Comparison of mechanism and functional effects of magnesium and statin pharmaceutical. J Am CollNutr 2004; 23[5]: 5015-5055.

[6]. Carman GM and Han GS. Roles of phosphatidate phosphatase enzymes in lipid metabolism. Trends BiochemSci 2006; 31[12]: 6949.

[7]. Salem M, Kholoussi S, Kholoussi N and Fauzy R. Malondialdehyde and trace element levels in patients with type 2 diabetes mellitus Archives of Hellenic medicine 2011; 28[1]: 83-88.

[8]. Sales CH and Campos Pedrosa LF. Magnesium and diabetes mellitus. Clinical Nutrition 2006; 25: 554-562.

[9]. Guize L, Le Heuzey J. Y, Blanchand D, Benoit MO, Pelissier E, Paris M, et al. Magnesium deficiencies in Cardiovascular disease. Arch Mal Coeur Vaiss 1984; 77: 41-47.

[10]. Sasmita Mishra, P. Padmanaban, G.N. Deepti, G.Sarkar, S. Sumathi, B.D. Toora Serum Magnesium and Dyslipidemia in Type-2 Diabetes Mellitus.Biomedical Research 2012; 23 (2): 295-300.

[11]. Nasri H and Hamid-Reza Baradaran. Lipids in association with serum magnesium in diabetes mellitus patients. BratislLekListy 2008; 109[7]: 302-206

[12]. Rashad. J. Belin and Ka He. Magnesium physiology and pathogenic mechanisms that contribute to the development of the metabolic syndrome. Magnesium research 2007; 20[2]: 107-29.

[13]. Haglin L, Backman L and Tornkvist B. A. structural equation model for assessment of links between changes in serum triglycerides, urate, glucose and changes in calcium, phosphate and magnesium in type 2 diabetes and non-diabetes metabolism. Cardiovascular Diabetology 2011; 10: 116.

[14]. Rasheed H, Elahi S and Ajay H. Serum magnesium and atherogenic lipid fractions in type 2 diabetic patients of Lahore, Pakistan. Biol Trace Elem Res 2012; 148[2]: 165-9.

[15]. Mishra S, Padmanaban P, Deepti GN, Sarkar G, Sumathi S and Toora BD. Serum magnesium and dyslipidemia in type 2 diabetes mellitus. Biomedical research 2012; 23[2]: 295-300.

[16]. Aruna $\mathrm{V}$ and Ambikadevi K. Hypomagnesemia a cofactor for atherogenesis in non insulin dependent diabetes mellitus. Int J Pharm Bio Sci 2014; 5[1]: 193-200.

[17]. Guerrero-Romero F, Tamez-Perez HE, Gonzalez-Gonzalez G et al. Oral magnesium supplementation improves insulin sensitivity in non-diabetic subjects with insulin resistance. A double-blind placebo-controlled randomized trial. Diabetes Metab. 2004 Jun;30(3):253-8. 